\title{
Antibiotic Resistance and Chromosomal Variation in Equine Faecal Salmonella spp.
}

\author{
Mohamed O. Ahmed ${ }^{1,2^{\star}}$, Nicola J. Williams ${ }^{2}$, Peter D. Clegg ${ }^{2}$ \\ and Malcolm Bennett ${ }^{3}$ \\ ${ }^{1}$ Department of Microbiology and Parasitology, Faculty of Veterinary Medicine, University of \\ Tripoli, P.O. Box 13662, Tripoli, Libya. \\ ${ }^{2}$ Department of Comparative Molecular Medicine School of Veterinary Science, University of \\ Liverpool, Leahurst, Chester High Road, Neston, CH64 7TE, UK. \\ ${ }^{3}$ Department of Animal and Population Health, School of Veterinary Science, University of \\ Liverpool, Leahurst, Chester High Road, Neston, CH64 7TE, UK.
}

\begin{abstract}
Authors' contributions
This work was carried out in collaboration between all authors. MOA designed the study, carried the experiments, the analysis, and wrote the first draft of the manuscript. NJW, PDC and $M B$ contributed to the study design, the analysis of the results and writing the manuscript. All authors read and approved the final manuscript.

Research Article

Received $1^{\text {st }}$ March 2012

Accepted $18^{\text {th }}$ May 2012

Published 23 ${ }^{\text {rd }}$ August 2012
\end{abstract}

\section{ABSTRACT}

Aims: Equine hospital Salmonella spp. were investigated retrospectively using antibiotic resistance typing and macro-restriction pulsed field gel electrophoresis techniques.

Study Design: Retrospective study.

Place and Duration of Study: Department of Comparative Molecular Medicine and department of Animal and Population Health, School of Veterinary Science, University of Liverpool.

Methodology: Twenty four achieved Salmonella isolates of equine faecal origin, previously collected from a UK equine hospital, were serotyped, phagetyped and tested both for antimicrobial susceptibility, by disc diffusion (BSAC) and for genetic relatedness by Xbal l-PFGE.

Results: Most isolates were Salmonella typhimurium ( $n=21)$, including five DT104; two were Salmonella enteritidis, and one was untypeable. Sixteen isolates, including five Salmonella typhimurium DT104 isolates exhibiting the classic penta-resistance 
phenotype (ACSSuT), were characterized as multidrug resistant (MDR). Fourteen MDR isolates showed additional resistance to florfenicol, although no resistance to ciprofloxacin was detected. MDR isolates showed two dominant resistance phenotypes: ACTSSuFlo $(\mathrm{N}=8)$ resistant to ampicillin, chloramphenicol, tetracycline, trimethoprim, streptomycin, sulfamethoxazole and florfenicol and ACTTrSSuFlo $(\mathrm{N}=6)$ which is also resistant to trimethoprim. Dendrogram analysis identified eleven distinct genetic groups showing an overall similarity of $84 \%$. The dominant resistance phenotypes were located mainly in two genetic groups: ACTSSuFlo isolates were all collected in the same year and were restricted to one clonal PFGE group showing $>99.5 \%$ genetic similarity; ACTTrSSuFlo isolates were genetically more diverse with $4 / 6$ clustering in a closelyrelated group showing $94 \%$ similarity.

Conclusion: These findings suggest that although some Salmonella infections were introduced to the hospital from outside, infections spreading within the equine hospital could also be a reservoir of MDR Salmonella zoonotic infections and play a role in the development and dissemination of antibiotic resistance.

Keywords: Zoonotic enteric bacteria; antimicrobial resistance; DT104; multidrug resistant Salmonella; PFGE.

\section{INTRODUCTION}

Salmonella is a zoonotic organism, and a serious public and animal health concern (Singh et al., 2009). Salmonella is also an important nosocomial pathogen of hospitalized horses (Dargatz and Traub-Dargatz, 2004; Ekiri et al., 2009), responsible for enteric gastrointestinal diseases (Ernst et al., 2004). Although Salmonella is rarely detected in healthy horses (Pichner et al., 2005), Salmonellae remain major contributors to acute enteric disease, responsible for many cases of diarrhoea in horses (Kim et al., 2001). Furthermore, horses can be asymptomatic carriers, shedding Salmonella in their faeces (Sanchez et al., 2002). Horses admitted to hospitals are likely to be more at risk of Salmonella infection due to stressors, such as surgery, antibiotic therapy (Ernst et al., 2004) or a combination of these factors, (Ekiri et al., 2009) making them more likely to shed bacteria. Horses can be a source of infection with Salmonella and several studies have documented zoonotic transmission to humans (Hoelzer et al., 2011).

Emergence of multi-drug-resistance (MDR) is a global problem, particularly in pathogens causing nosocomial infections (Ahmed et al., 2012; Singh et al., 2009) including several Salmonella serovars (Zhao et al., 2007). Antimicrobial therapy has been shown to influence the excretion and transmission of multidrug resistance (MDR) both in humans and animals (Ahmed et al., 2012). In humans, Salmonella enterica typhimurium and Salmonella enteriditis are the most common serovars associated with gastroenteritis and Salmonella enterica serovar typhimurium definitive phage type 104 (DT104) is frequently isolated from food animals (Lawson et al., 2004). Recently, the increase in MDR-Salmonella has been especially important owing to the emergence of the multi-resistant Salmonella typhimurium DT104 in both humans and animals. Worldwide human outbreaks of different Salmonella species exhibiting an MDR phenotype are reported to have zoonotic origins (Rayamajhi et al., 2008), related to the consumption of animals products including horse meat (Espie et al., 2005; Doorduyn et al., 2008). 
Molecular and antibiotic resistance studies of Salmonella from horses are limited in comparison to human and other animal studies (Ahmed et al., 2009; Zhao et al., 2007). The aim of this retrospective analysis is to investigate the possible source of Salmonella infections in an equine hospital and investigating the antibiotic resistance and genetic relatedness amongst archived Salmonella isolates.

\section{MATERIALS AND METHODS}

Twenty four isolates of Salmonella spp. of faecal origin, were obtained from the Philip Leverhulme Equine Hospital (PLEH) archive for analysis. Isolates were originally derived from faecal samples, collected between 1995-2000, at the PLEH, University of Liverpool. These had already been isolated and confirmed using selective laboratory methods and further confirmed as Salmonella spp. by agglutination tests and Api20E, using Salmonella typhimurium DWC 2578 as a positive control. Isolates were serotyped and phagetyped by the Department of Medical Microbiology, University of Liverpool and the Veterinary Laboratory Agency (VLA-UK). Antibiotic susceptibility was determined by disc diffusion testing in accordance with BSAC guidelines as described (Andrews, 2008). Florfenicol resistance in chloramphenicol resistant isolates we characterized using a criterion of $\mathrm{R} \leq 18 \mathrm{~mm}$, following personal communication with J.M. Andrews. Isolates that exhibited resistance to at least four drugs were characterized as multidrug resistant MDR. Antibiotics tested were - ampicillin $(10 \mu \mathrm{g})$, apramycin $(30 \mu \mathrm{g})$, chloramphenicol $(30 \mu \mathrm{g})$, florfenicol $(30 \mu \mathrm{g})$, tetracycline $(10 \mu \mathrm{g})$, trimethoprim $(2.5 \mu \mathrm{g})$, streptomycin $(10 \mu \mathrm{g})$, Sulphamethoxazole $(100 \mu \mathrm{g})$, gentamicin $(10 \mu \mathrm{g})$, nalidixic acid $(30 \mu \mathrm{g})$ and ciprofloxacin $(1 \mu \mathrm{g})$.

Phylogenetic relatedness of the 24 isolates was investigated using macrorestriction PFGE analysis: DNA extraction, Xbal digestion and PFGE were all performed according to (Schott et al., 2001). Data were obtained from the digital gel image using Quantity One and Diversity Database software (Bio-Rad). Genetic distance calculations were based on band sharing and relationships calculated using the unweighted pair group method with averages (UPGMA), with Nei's coefficient. UPGMA data was then used to construct dendrogram showing the genetic relationship between the different isolates.

\section{RESULTS AND DISCUSSION}

Of the 24 isolates, 21 were Salmonella enterica serotype typhimurium, of which five were Salmonella typhimurium DT104; two were Salmonella enteritidis and one was non-typable (Table 1).

All isolates were resistant to at least one antimicrobial agent (tetracycline). 75\% (16/24) were MDR, i.e. resistant to at least four antibiotics; of these, all except one were Salmonella typhimurium. $88 \%$ of the MDR isolates shared the penta phenotype ACSSuT, Among the 16 MDR isolates, two phenotypes predominated, ACTTrSSuFLO $(\mathrm{N}=6)$ and ACTSSuFLO $(\mathrm{N}=8)$, with five of the latter confirmed as phagetype DT104. Two further MDR isolates had the phenotype TTrSSuN (Table 1). 
Table 1. Serotype, phage type and antibiotic resistance phenotypes of archived Salmonella from horses at the PLEH equine hospital

\begin{tabular}{|c|c|c|c|c|}
\hline No. & Year & Phagetype & Serotype & AMs resistant profile (ph) \\
\hline 1 & 1995 & 104 & typhimurium & ACTTrSSuNFlo ${ }^{\text {MDR }}$ \\
\hline 2 & 1995 & 4 & enteritidis & TSu \\
\hline 3 & 1995 & - & typhimurium & ATSu \\
\hline 4 & 1995 & - & untypable & TTrSSuN ${ }^{M D R}$ \\
\hline 5 & 1995 & 193 & typhimurium & TTrSSuN ${ }^{M D R}$ \\
\hline 6 & 1995 & - & typhimurium & TSu \\
\hline 7 & 1996 & & typhimurium & TSu \\
\hline 8 & 1996 & - & typhimurium & ACTTrSSuFlo ${ }^{\text {MDR }}$ \\
\hline 9 & 1996 & 6 & typhimurium & ACTTrSSuFlo ${ }^{M D R}$ \\
\hline 10 & 1996 & 104 & typhimurium & ACTTrSSuFlo ${ }^{M D R}$ \\
\hline 11 & 1996 & - & typhimurium & ACTTrSSuFlo ${ }^{M D R}$ \\
\hline 12 & 1997 & 104 & typhimurium.typ & ACTSSuFlo \\
\hline 13 & 1997 & - & himurium & ACTSSUFlo ${ }^{M D R}$ \\
\hline 14 & 1997 & - & typhimurium & ACTSSUFIo ${ }^{M D R}$ \\
\hline 15 & 1997 & - & typhimurium & ACTSSUFlo ${ }^{M D R}$ \\
\hline 16 & 1997 & - & typhimurium & ACTSSuFlo ${ }^{M D R}$ \\
\hline 17 & 1997 & - & typhimurium & ACTSSUNFIo ${ }^{M D R}$ \\
\hline 18 & 1997 & - & .typhimurium & ACTSSuFlo MDR \\
\hline 19 & 1997 & - & .typhimurium & $\mathrm{T}$ \\
\hline 20 & 1998 & 104 & typhimurium & ACTSSuFlo ${ }^{M D R}$ \\
\hline 21 & 1998 & 195 & .typhimurium & $\mathrm{T}$ \\
\hline 22 & 1999 & - & .enteritidis & $\mathrm{T}$ \\
\hline 23 & 2000 & - & .typhimurium & $\mathrm{T}$ \\
\hline 24 & 2000 & 104 & typhimurium & ACTTrSSuFlo ${ }^{M D R}$ \\
\hline
\end{tabular}

*Abbreviations: $-=($ non $), A M s=($ Antimicrobials $), A=($ Ampicillin $), C=($ Chloramphenicol $), T=$

(Tetracycline), $S=($ Streptomycin $), S u=($ Sulfamethoxazole $), T r=($ Trimethoprim $), N=($ Nalidixic acid), Flo $=($ Florfenicol $),{ }^{\text {MDR }}=($ Multidrug resistant $)$

Antibiotics tested were - ampicillin (A) $(10 \mu \mathrm{g})$, apramycin (Apr) $(30 \mu \mathrm{g})$, chloramphenicol (C) $(30 \mu \mathrm{g})$, florfenicol (Flo) $(30 \mu \mathrm{g})$, tetracycline $(\mathrm{T})(10 \mu \mathrm{g})$, trimethoprim (Tr) $(2.5 \mu \mathrm{g})$,

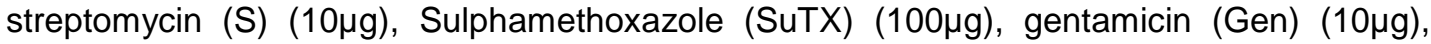
nalidixic acid (Nal) $(30 \mu \mathrm{g})$ and ciprofloxacin (Cip) $(1 \mu \mathrm{g})$.

PFGE analysis showed several different genotypes, although one genotype predominates. Dendrogram analysis of Xbal banding patterns indicates that the 24 isolates shared $>84 \%$ identity overall and could be divided into eleven clades (PFGE groups) according to the similarity of the banding pattern.

Fig.1 shows dendrogram analysis and antibiogram profiles of Salmonella enterica isolates: genetic similarity calculations used to construct the dendrogram were based on band sharing, determined from PFGE of Xbal fragments. Antibiotic resistance patterns were derived from MIC determinations; grey bars represent resistance. Abbreviations: A, ampicillin; C, chloramphenicol; T, tetracycline; Tr, trimethoprim; S, streptomycin; Su, sulphamethoxazole; N, nalidixic acid; F, florfenicol. 


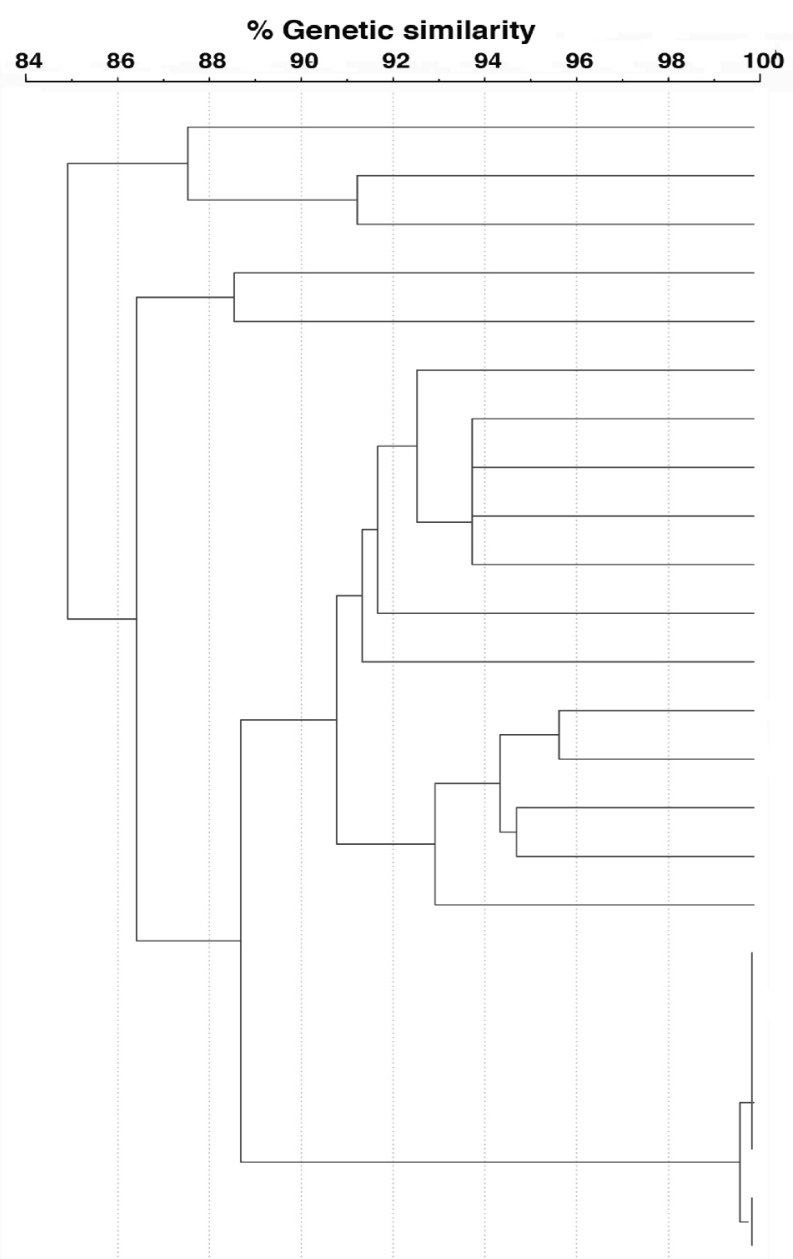

Isolate
1
2
23
3
22
4
8
9
10
11
7
21
5
17
6
19
24
12
13
14
15
16
18
20

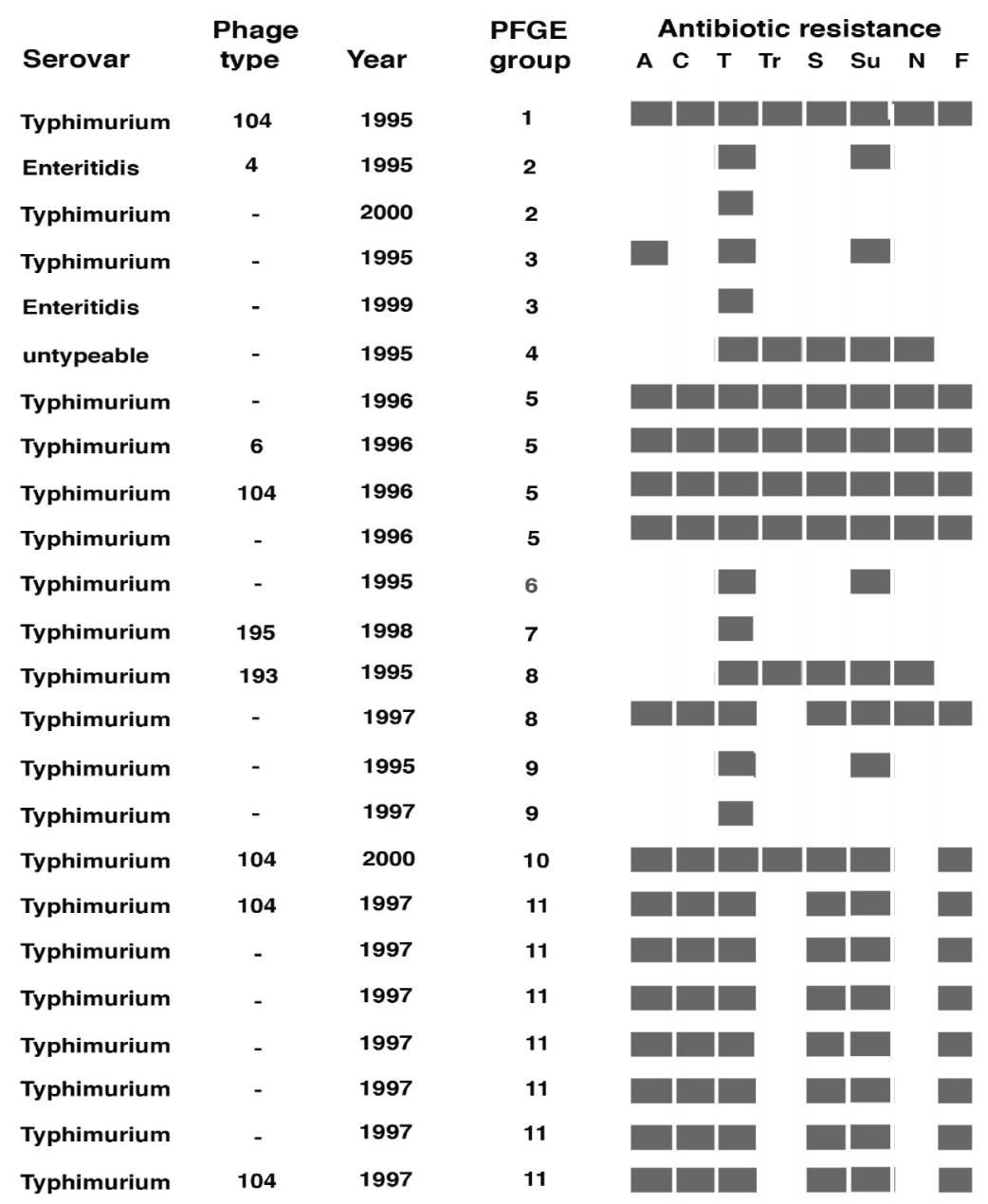

Fig.1. Dendrogram analysis and antibiogram profiles of Salmonella enterica isolates 
$5 / 11$ patterns were unique, a further $5 / 11$ were each represented by two isolates. However, $30 \%(7 / 24)$ of the isolates fell into one clade, PFGE group 11. These isolates in PFGE group 11 were all collected in 1997 and showed a genetic similarity of $>99.5 \%$. All these isolates were MDR and showed identical antibiotic resistance profiles. The clonal nature of these isolates suggests that they may represent an endemic strain circulating in the equine hospital at that time. A further cluster of four isolates (PFGE group 5) was identified amongst isolates recovered in 1996. This group of isolates is more varied genetically, showing $94 \%$ similarity and having three different phage types, nevertheless, all are MDR and share identical antibiotic resistance patterns. When this is combined with the susceptibility testing results, this would suggest that isolates recovered in 1996 may represent an epidemic of MDR Salmonella, including DT104.

Most of the isolates were Salmonella typhimurium, the serovar most commonly reported in horses, in which MRD is increasingly prevalent (Van Duijkeren et al., 2002) and which is responsible for both human and animal outbreaks in Europe (Horby et al., 2003; Van Duijkeren et al., 2002). The use of PFGE for identifying genetic relatedness and possible clustering of MDR Salmonella typhimurium DT104 in animals is well-established (Zeng et al., 2011) and susceptibility testing is recognized as an important component of any preliminary identification of MDR Salmonella strains especially Salmonella typhimurium DT104 (Thorsteinsdottir et al., 2007). The resistance patterns identified in our isolates are similar to other studies of MDR Salmonella DT104 in horses, where the resistance pattern ACSSUT is the most widely reported (Van Duijkeren et al., 2002).

Many studies have shown the increasing prevalence of antibiotic resistance in Salmonella typhimurium in both farm animals and humans (Dargatz and Traub-Dargatz, 2004; Zeng et al., 2011). All the Salmonella in this study were resistant to at least one antibiotic and many were multidrug resistant. Two distinctive resistance phenotypes were noticed among the multidrug resistant isolates: ACTTrSuFlo and ACTSuFlo. These were similar to the resistance profiles of Salmonella typhimurium from two human outbreaks in England in 2000 (Horby et al., 2003) and also were attributed to the consumption of contaminated food of equine origin in Netherlands (Van Duijkeren et al., 2002). Recent increases in MDRSalmonella have been of particular importance owing to the emergence of the multi-resistant Salmonella typhimurium DT104 in both humans and animals (Lawson et al., 2004; Rayamajhi et al., 2008). Although MDR-Salmonella types, especially DT104, have been associated with meat consumption and contact with infected animals (Espie et al., 2005) (Doorduyn et al., 2008), our findings also suggest that horse faeces could be a potential source of human MDR Salmonella infections.

Trimethoprim resistance in salmonellas has been attributed to the use of this agent to combat the emergence of DT104 in cattle in the UK, so finding trimethoprim resistance among equine salmonellae may suggest that these isolates originated in food animals, or might have acquired this resistance type through genetic elements originating from food animal bacteria. Similarly, florfenicol is not licensed for use in horses, but it is licensed for cattle with respiratory infections. Salmonella typhimurium DT104 with floSt have been isolated from many different animals including horses (Hall, 2010). In this study, florfenicol resistance was detected using disk diffusion method in MDR salmonellas, suggesting that this resistance might be encoded within MDR system, which probably, again, originated in food animals. It is well documented that MDR is most likely to be related to the carriage of integrons, as in the case of DT104, and horizontal transfer of these genes might have occurred. The possibility of transfer of plasmids amongst salmonellae in the intestinal tract of 
humans has been reported as has transfer of resistance between different organisms such as Salmonella and E. coli (Winokur et al., 2001).

The Salmonella isolates we describe had been collected from horses intermittently over the years to produce the archive used in this study. Aside from clusters of genetically related strains isolated in 1996 and 1997, the variation in resistance phenotypes and in PFGE profiles suggests that salmonellosis was probably introduced episodically by individual horses. On the other hand, the cluster of four isolates sharing $94 \%$ genetic similarity and having identical antibiotic resistance profiles suggests that in that year (1996) there may have been an 'epidemic' of equine salmonellas coming into the hospital, probably as the result of spill-over of salmonellosis from other species. Samples recovered in 1997, also show identical antibiotic resistance profiles, but are distinct from the 1996 cluster, In the 1997 cluster, the very tight genetic similarity (>99.5\% identity) of the isolates in this clade, suggests that these may represent an endemic outbreak in the hospital.

\section{CONCLUSION}

Overall, this study shows that the resistance phenotype of Salmonella can be a useful epidemiological tool, especially when combined with molecular techniques. The MDR isolates in this study appeared to be closely related and probably represent spillover into horses of an epidemic of MDR salmonellas, including DT104, in other domestic animals and humans. The MDR phenotypes in equine fecal samples complicates the use and selection of antibiotic drugs for treatment of clinical equine Salmonella infections and indicates that horses in a hospital setting may be a source of zoonotic MDR Salmonella infection for humans.

\section{CONSENT}

Authors declare that 'written informed consent was obtained from the patient (or other approved parties) for publication of this paper.

\section{ETHICAL APPROVAL}

All authors hereby declare that all experiments have been examined and approved by the appropriate ethics committee and have therefore been performed in accordance with the ethical standards laid down in the 1964 Declaration of Helsinki.

\section{ACKNOWLEDGEMENTS}

Authors are grateful to all staff members at Philip Leverhulme Equine Hospital (PLEH) and the livery stables for their help and support throughout this work. 


\section{COMPETING INTERESTS}

The authors declare no relationship (commercial or otherwise) that may constitute a dual or conflicting interest.

\section{REFERENCES}

Ahmed, M.O., Williams, N.J., Clegg, P.D., van Velkinburgh, J.C., Baptiste, K.E., Bennett, M. (2012). Analysis of risk factors associated with antibiotic-resistant Escherichia coli. Microb Drug Resist. [Epub ahead of print].

Ahmed, A.M., Shimabukuro, H., Shimamoto, T., (2009). Isolation and molecular characterization of multidrug-resistant strains of Escherichia coli and Salmonella from retail chicken meat in Japan. J. Food. Sci., 74, M405-410.

Andrews, J.M. (2008). BSAC standardized disc susceptibility testing method (version 7). J. Antimicrob. Chemother., 62, 256-278.

Bolton, L.F., Kelley, L.C., Lee, M.D., Fedorka-Cray, P.J., Maurer, J.J. (1999). Detection of multidrug-resistant Salmonella enterica serotype typhimurium DT104 based on a gene which confers cross-resistance to florfenicol and chloramphenicol. J. Clin. Microbiol., 37, 1348-1351.

Dargatz, D.A., Traub-Dargatz, J.L. (2004). Multidrug-resistant Salmonella and nosocomial infections. Vet. Clin. North. Am. Equine. Pract., 20, 587-600.

Doorduyn, Y., Hofhuis, A., DE jager, C., Van der zwaluw, W., Notermans, D., Van pelt, W., (2008). Salmonella typhimurium outbreaks in the Netherlands in 2008. Euro. Surveill., 13, pii: 19026.

Ekiri, A.B., Mackay, R.J., Gaskin, J.M., Freeman, D.E., House, A.M., Giguere, S., Troedsson, M.R., Schuman, C.D., Von chamier, M.M., Henry, K.M., Hernandez, J.A., (2009). Epidemiologic analysis of nosocomial Salmonella infections in hospitalized horses. J. Am. Vet. Med. Assoc., 234, 108-119.

Ernst, N.S., Hernandez, J.A., Mackay, R.J., Brown, M.P., Gaskin, J.M., Nguyen, A.D., Giguere, S., Colahan, P.T., Troedsson, M.R., Haines, G.R., Addison, I.R., Miller, B.J., (2004). Risk factors associated with fecal Salmonella shedding among hospitalized horses with signs of gastrointestinal tract disease. J. Am. Vet. Med. Assoc., 225, 275281.

Espie, E., De valk, H., Vaillant, V., Quelquejeu, N., Le querrec, F., Weill, F.X. (2005). An outbreak of multidrug-resistant Salmonella enterica serotype Newport infections linked to the consumption of imported horse meat in France. Epidemiol. Infect., 133, 373376.

Hall, R.M. (2010). Salmonella genomic islands and antibiotic resistance in Salmonella enterica. Future Microbiol., 2010 Oct; 5(10), 1525-38.

Hoelzer, K., Moreno, Switt, A.I., Wiedmann, M. (2011). Animal contact as a source of human non-typhoidal salmonellosis. Vet Res., Feb 14, 42(1), 34.

Horby, P.W., O'brien, S.J., Adak, G.K., Graham, C., Hawker, J.I., Hunter, P., Lane, C., Lawson, A.J., Mitchell, R.T., Reacher, M.H., Threlfall, E.J., Ward, L.R. (2003). A national outbreak of multi-resistant Salmonella enterica serovar Typhimurium definitive phage type (DT) 104 associated with consumption of lettuce. Epidemiol. Infect., 130, 169-178.

Kim, L.M., Morley, P.S., Traub-Dargatz, J.L., Salman, M.D., Gentry-Weeks, C. (2001). Factors associated with Salmonella shedding among equine colic patients at a veterinary teaching hospital. J. Am. Vet. Med. Assoc., 218, 740-748. 
Lawson, A.J., Desai, M., O'brien, S.J., Davies, R.H., Ward, L.R., Threlfall, E.J. (2004). Molecular characterisation of an outbreak strain of multiresistant Salmonella enterica serovar Typhimurium DT104 in the UK. Clin. Microbiol. Infect., 10, 143-147.

Pichner, R., Sander, A., Steinruck, H., Gareis, M. (2005). Occurrence of Salmonella spp. and shigatoxin-producing Escherichia coli (STEC) in horse faeces and horse meat products. Berl Munch Tierarztl Wochenschr, 118, 321-325.

Rayamajhi, N., Kang, S.G., Kang, M.L., Lee, H.S., Park, K.Y., Yoo, H.S. (2008). Assessment of antibiotic resistance phenotype and integrons in Salmonella enterica serovar Typhimurium isolated from swine. J. Vet. Med. Sci., 70, 1133-1137.

Sanchez, S., Hofacre, C.L., Lee, M.D., Maurer, J.J., Doyle, M.P. (2002). Animal sources of salmonellosis in humans. J. Am. Vet. Med. Assoc., 221, $492-497$.

Schott, H.C., Ewart, S.L., Walker, R.D., Dwyer, R.M., Dietrich, S., Eberhart, S.W., Kusey, J., Stick, J.A., Derksen, F.J. (2001). An outbreak of salmonellosis among horses at a veterinary teaching hospital. J. Am. Vet. Med. Assoc., 218, 1152-1159, 1100.

Singh, B.R., Jyoti, J., Chandra, M., Babu, N., Sharma, G. (2009). Drug resistance patterns of Salmonella isolates of equine origin from India. J Infect Dev Ctries., 1; 3(2), 141-7.

Thorsteinsdottir, T.R., Kristinsson, K.G., Gunnarsson, E. (2007). Antimicrobial resistance and serotype distribution among Salmonella spp. in pigs and poultry in Iceland, 20012005. Microb Drug Resist., 13, 295-300.

Threlfall, E.J., Ward, L.R.(2001). Decreased susceptibility to ciprofloxacin in Salmonella enterica serotype typhi, United Kingdom. Emerg. Infect. Dis., 7, 448-450.

Van duijkeren, E., Wannet, W.J., Heck, M.E., Van pelt, W., Sloet van oldruitenborghoosterbaan, M.M., Smit, J.A., Houwers, D.J. (2002). Sero types, phage types and antibiotic susceptibilities of Salmonella strains isolated from horses in The Netherlands from 1993 to 2000. Vet. Microbiol., 86, 203-212.

Winokur, P.L. Vonstein, D.L. Hoffman, L.J. Uhlenhopp, E.K. Doern, G.V. (2001). Evidence for transfer of CMY-2 AmpC beta-lactamase plasmids between Escherichia coli and Salmonella isolates from food animals and humans. Antimicrob Agents Chemother, 45(10), 2716-2722.

Zhao, S., Mcdermott, P.F., White, D.G., Qaiyumi, S., Friedman, S.L., Abbott, J.W., Glenn, A., Ayers, S.L., Post, K.W., Fales, W.H., Wilson, R.B., Reggiardo, C., Walker, R.D. (2007). Characterization of multidrug resistant Salmonella recovered from diseased animals. Vet. Microbiol., 123, 122-132.

Zheng, J., Keys, C.E., Zhao, S., Ahmed, R., Meng, J., Brown, E.W. (2011). Simultaneous analysis of multiple enzymes increases accuracy of pulsed-field gel electrophoresis in assigning genetic relationships among homogeneous Salmonella strains. J. Clin Microbiol., 49, 85-94.

(C) 2012 Ahmed et al.; This is an Open Access article distributed under the terms of the Creative Commons Attribution License (http://creativecommons.org/licenses/by/3.0), which permits unrestricted use, distribution, and reproduction in any medium, provided the original work is properly cited. 